\title{
Concepções de uma estética materialista para uma arte transformadora: a superação do caráter abstrato na particularidade do trabalho artístico
}

\author{
Conceptions of a materialist aesthetics for a transforming art: the overcoming of the \\ abstract nature in the particularity of the artistic work
}

Wescley Silva Xavier ${ }^{1}$

Alexandre de Pádua Carrieri ${ }^{2}$

\section{Resumo}

Este artigo tem como objetivo resgatar as bases de uma estética materialista - principalmente, as desenvolvidas por György Lukács - que lance luz sobre a produção artística como elaboração da própria realidade, e que, por consequência, se configure num instrumento de auxílio à superação das contradições materiais. Partimos do pressuposto de que a dominação cultural representa uma extensão do poder que o capital exerce sobre o trabalho, reduzindo as possibilidades de transformação a partir das elaborações artísticas. A partir do movimento dialético entre base e superestrutura, a produção artística como reflexo da realidade pode estabelecer um caráter transformador da vida social, desde que a obra de arte represente de maneira efetiva possibilidades de contrapor e superar as contradições existentes no capital quando recobra seu caráter objetivo na própria vida humana.

Palavras-chave: Estudos Organizacionais. Marxismo. Estética Materialista. Produção Artística.

\begin{abstract}
This article aims to rescue the principles of a materialist aesthetic - mainly those ones developed by György Lukács that focuses on the artistic production as an elaboration of its own reality, and as a consequence, becomes an aid instrument that supports the overcoming of material contradictions. We assumed here that cultural domination is an extension of the power of capital over labor, reducing the possibility of transformation through artistic elaborations. From the dialectic movement between basis and superstructure, the artistic production as a reflection of reality may become a transformative force in society, considering that the masterpiece represents in an effective way possibilities to oppose and overcome the contradictions in capital when it regains its objective character in human life.
\end{abstract}

Keywords: Organizational Studies. Marxism. Materialist Aesthetics. Artistic Production.

Artigo submetido em 14 de janeiro de 2014 e aceito para publicação em 28 de abril de 2014.

DOI: http://dx.doi.org/10.1590/1679-395115007

Agradecemos ao CNPq pela bolsa de doutorado e a Elcemir Paço-Cunha, professor da UFJF, pelas contribuições imprescindíveis a este trabalho.

${ }^{1}$ Doutor em Administração pelo CEPEAD/UFMG; Professor Adjunto da Universidade Federal de Viçosa. Endereço: Av. P.H. Rolfs, s/n, Depto de Administração e Contabilidade, Campus Universitário, CEP 36570-900, Viçosa - MG, Brasil. E-mail: wescleysxavier@yahoo.com.br

2 Doutor em Administração pelo CEPEAD/UFMG; Professor Titular da Universidade Federal de Minas Gerais. Endereço: UFMG, Faculdade de Ciências Econômicas. Av. Antônio Carlos, 6627, Pampulha, CEP: 31270-901, Belo Horizonte - MG, Brasil. E-mail: alexandre@face.ufmg.br 


\section{Introdução}

Antes reservados a outras áreas das ciências humanas, estudos que abarcam a produção artística, obra de arte, produção cultural e política cultural têm sido inseridos de forma cada vez mais intensa no campo da administração. Isso ocorre por um viés mais conservador, segundo uma lógica mercantilista que entende tratar-se de um segmento a ser explorado comercialmente. Isso se deve não apenas ao próprio caráter de mercadoria atribuído à arte, mas também pela aproximação de empresas privadas dessa questão, particularmente, através da criação de fundações culturais que garantem o lastro "social" do capital. Segundo essa mesma ótica, e quase como complemento, a produção artística tem se tornado lugar comum na esfera da gestão pública, fundamentalmente, pela inocuidade das ações governamentais nesse campo e pelo interesse de grupos econômicos em "sanar" essa lacuna.

Ponto comum (tanto no aspecto mercantil da arte quanto da aproximação dos grupos supracitados diante das manifestações culturais) é a conservação de um caráter restritivo da produção/consumo do produto cultural, exceto quanto às produções que se enquadram na lógica da indústria cultural esboçada por Adorno e Horkheimer (1985). Dessa forma, inaugura-se uma escala intervalar relativamente esvaziada de intermédios, pautada somente pelos extremos da cultura de massa e da cultura erudita. A primeira, de certa maneira, é tratada como um subterfúgio às frustrações cotidianas, enquanto à segunda é reservado o rótulo de elaborada a partir de um pressuposto racional e academicista, quase inatingível por uma parcela significativa da população desprovida de educação artística formal.

Especificamente sobre o caráter distintivo da atividade artística, observa-se que tanto a arte quanto a ciência têm sido colocadas como espectros ultra-humanos no decorrer da história. A busca pela distinção de classes dominantes e o advogar das atividades exercidas por parte dessas classes, num ordenamento que assume um ar de naturalidade, são responsáveis por estabelecer quem deve empregar seus esforços no processo de transformação produtiva clássico e aqueles que destinam seu tempo ao desenvolvimento de formulações científicas e artísticas. É essa a verdadeira divisão do trabalho, que separa o trabalho físico do intelectual, que se constitui numa aparente autonomia fundante de toda espiritualidade que representa algo que não é real, num exercício de emancipação da vida material ao propósito da teorização abstrata, consciência sem práxis (MARX e ENGELS, 2007).

Parte dessa classe dominante direciona seus esforços à atividade do pensamento, sendo essa parcela mais capacitada para formular ideias e ideologias prontamente convertidas em pilares para sua própria subsistência, no que Marx e Engels (2007, p. 47-48) classificam como "tarefa de criar a ilusão desta classe sobre si mesma". A outra parte adota, ante as ideias elaboradas, uma postura passiva e receptiva, "já que são os membros ativos da classe e dispõem de pouco tempo para construir ilusões e ideias sobre si mesmo". Ao considerarmos as elaborações políticas, religiosas, artísticas e científicas - entre outras - como componentes de uma superestrutura condicionada e condicionante das relações produtivas, da base, é possível estabelecer o vínculo entre a operação dos elementos ideológicos da superestrutura e as relações de produção que fazem de um grupo classe dominante.

Embora o aspecto racional faça recair mais fortemente a divisão supracitada sobre o desenvolvimento científico, a elaboração artística deve necessariamente ser considerada objeto de reflexão por conter em si certa etapa do próprio desenvolvimento da humanidade, a partir de um ponto de vista materialista (LEFEBVRE, 2001). O objeto artístico desenvolve uma função complementar e ao mesmo tempo subsidia o domínio de classe, uma vez que é parte constituinte de uma superestrutura que estabelece implicações múltiplas com a base. Em suma, a produção artística reflete as relações da vida material e suas contradições, operando como chancela do capital na esfera da superestrutura ou desvelando possibilidades de resistência e de transformação, a partir de uma produção que tenha um efetivo retorno sobre a base, as relações efetivamente materiais nas quais as contradições têm origem.

Não obstante o potencial da arte para que as contradições identificadas na base possam ser superadas em sua múltipla implicação com os elementos superestruturais, é intensa a imputação da manifestação artística como 
expressão subjetiva do homem capaz de deflagrar um processo transformador que se exaure no próprio indivíduo. Ademais, recorrentemente é atrelada à figura do artista certa genialidade e capacidade criativa que o distingue dos trabalhadores comuns cujo processo de transformação produtiva se baseia na própria capacidade corporal. Deflagra-se aqui a exata divisão do trabalho que oblitera as reais condições que permitem a alguns dedicar-se às atividades espirituais e a outros necessariamente emprenhar-se em atividades de produção essenciais para a vida. Nos termos de Marx (1996), assim como o operário individual pode oferecer mais trabalho excedente à medida que for menor seu tempo de trabalho necessário, dentro da totalidade de trabalho possível numa sociedade, quanto menor for a parcela de trabalho (em número de homens) exigido para a produção de bens essenciais à sobrevivência, maior o contingente de trabalho que pode ser destinado para outros trabalhos - como a arte e a ciência.

A diferenciação estabelecida entre a obra artística e o trabalho convencional, que faz da arte produto de elevada abstração (e por consequência, de compreensão limitada), só é possível porque o aspecto operacional da produção artística ancorado na base econômica atribui à arte a finalidade de fruição para a mesma classe que exerce domínio dos meios de produção, de forma que o próprio reconhecimento do que tem ou não valor artístico passa pelo crivo dessa mesma classe. Sua produção não se limita apenas a oferecer um objeto material que atenda a necessidades, mas também provê uma necessidade aos objetos materiais produzidos (MARX, 2008; 2011).

Portanto, o complemento das funções de produção e consumo do trabalho artístico e de fruição da classe dominante está na produção do objeto para o sujeito. Esta, por sua vez está ancorada tanto no status quo balizado pela superestrutura determinada (não mecanicamente) conforme o atual estágio do modo de produção, quanto na criação de um público capaz de fruir o estágio de desenvolvimento da arte.

O resultado da abstração do produto artístico e do próprio processo de produção, que surgem descompromissados com as relações materiais da vida, converge com a necessidade de se criar um aparato superestrutural que combine com as contradições impostas pelo capital. O valor de uso e particularmente o de troca da obra recaem sobre os aspectos estéticos que apontam para o "belo" e o "excepcional", revestido de um intenso processo de subjetivação da consciência que abstrai a própria realidade. É justamente o caráter abstrato-subjetivo da produção artística que uma concepção materialista da estética permite superar, uma vez que, a partir do elo inexorável entre base e superestrutura, atribui à elaboração artística o necessário reflexo da realidade e de suas contradições. A partir desse pressuposto, a produção artística transmutaria de seu caráter mantenedor das contradições geradas pelo capital para uma via de reflexão e superação dos problemas e conflitos oriundos da relação entre capital e trabalho.

Considerando essa possibilidade, buscamos resgatar neste artigo as bases de uma estética materialista que lance luz sobre a produção artística como elaboração da própria realidade, e que por consequência, se configure num instrumento que auxilia a superação das contradições materiais. É necessário ressaltar, entretanto, que recobramos aqui a exata localização da arte como parte de um processo de desenvolvimento histórico que opera dialeticamente em seu conteúdo interno - diante de outras elaborações artísticas com as quais se estabelece conflito - e em seu conteúdo externo, num retorno à própria vida material.

O percurso trilhado neste artigo contempla quatro seções. A primeira trata dos fundamentos de uma estética materialista marxista, especialmente, aqueles desenvolvidos pelo filósofo húngaro György Lukács. Em seguida, focamos a questão da particularidade na estética e seus elementos subjetivos. Na quarta seção recobramos a tomada de posição através da obra de arte e seu potencial como autoconsciência do desenvolvimento do ser social. Por fim, retomamos os apontamentos mais importantes nas considerações finais. 


\section{Aspectos Fundamentais para uma Estética Marxista}

A incursão marxista pela estética pode soar estranha aos desavisados da intensa dedicação tanto de Marx quanto de Engels ao estudo dos processos históricos de formação econômica; particularmente, das relações de produção, circulação e consumo de mercadorias em diversos momentos da evolução do capital. Entretanto, a organização do modo de produção não está dissociada de outras esferas da vida humana, sendo engendrada e mantendo relação com outras nuanças constitutivas da superestrutura. A separação dos ramos particulares da ciência, da arte, comum ao mundo burguês, é rejeitada pela concepção marxista, de forma que esses elementos não apresentem uma história autônoma, exclusiva de sua dialética interior (LUKÁCS, 2010).

Para Marx (2008), na produção social da vida, os homens estabelecem relações determinadas que são necessárias e independem de sua vontade. Essas relações de produção correspondem a uma dada fase do desenvolvimento de suas forças produtivas materiais. A totalidade dessas relações de produção constitui a estrutura econômica da sociedade, sobre a qual se ergue uma superestrutura composta de aparatos jurídicos, políticos, filosóficos, religiosos e artísticos, entre outros, aos quais correspondem determinadas formas de consciência social. Assim, o modo de produção da vida material condiciona a produção da vida social. O ser não é determinado pela consciência do homem, mas sim o seu ser social é que determina a sua consciência (MARX, 2008; MARX e ENGELS, 2007), a partir da relação do ser com o mundo, das experiências e contradições apreendidas.

Por um constante mal-entendido se acredita em alguns instantes que a imagem do mundo, própria do materialismo - prioridade do ser frente à consciência, do ser social frente à consciência social - é também de caráter hierárquico. Para o materialismo, a prioridade do ser é, primeiramente, uma questão de fato; existe ser sem consciência, mas não consciência sem ser. (LUKÁCS, 1966a, p. 19)

A operacionalização da superestrutura é fundamentalmente importante na transição das próprias formas de produção da vida material. Marx (2008, p. 47) destaca que "em uma certa etapa do desenvolvimento, as formas produtivas materiais da sociedade entram em contradição com as relações de produção existentes", ou mesmo ante as "relações de propriedade no seio das quais elas se haviam desenvolvido até então". As relações de propriedade que antes sustentavam as forças produtivas colocam-se como entrave ao seu desenvolvimento, deflagrando, então, o período de revolução social. A transformação da base econômica implica a mudança da superestrutura que a ela estava conectada. Essa transformação na superestrutura engendra novas formas ideológicas - sejam elas jurídicas, filosóficas, religiosas, artísticas etc. - pelas quais os homens adquirem consciência desse conflito e lutam para resolvê-lo (MARX, 2008). Em seu caráter dialético-materialista, esses elementos da superestrutura que têm como base o desenvolvimento econômico interagem entre si, mas também reatuam sobre a base econômica (ENGELS, $1894^{3}$.)

Assim como o trabalho, a ciência e todas as atividades sociais, a arte é um produto do desenvolvimento social constituinte da superestrutura, sendo não apenas reflexo da realidade (portanto, dos modos de produção), mas também da tomada de consciência a respeito das contradições da vida social. Para Lukács (2010), a essência, a gênese e a eficácia da literatura - bem como das demais formas de expressão artística só podem ser compreendidas e explicadas dentro de um quadro histórico geral de todos os sistemas econômicos, políticos e artísticos, entre outros. Os movimentos artísticos são em si componentes do processo histórico geral da sociedade, o que, do ponto de vista da estética marxista, conduz ao materialismo histórico. A essência e o valor estético das obras de arte correspondem ao que o homem apreende do processo social conflitos, divisões de classe - através da consciência manifesta na interpretação/produção/significação artística, que nos conduz ao materialismo dialético (LUKÁCS, 1965; 2010).

\footnotetext{
${ }^{3}$ Carta de Engels a Starkenburg, de 25 jan. 1894 (MARX e ENGELS, 2010).
} 
Essa inter-relação entre as esferas diversas da vida, entre elas a arte, leva-nos ao materialismo histórico, de modo que possamos apreender os elementos constituintes do desenvolvimento da arte e do seu caráter estético, sua posição e operacionalização dentro da superestrutura. É necessário, pois, compreender que a produção artística nasce sobre uma base econômica a partir das relações determinadas de produção, ou seja, a partir de relações de propriedade (expressão jurídica das relações de produção) e das relações de classes determinadas (LEFEBVRE, 2001). Encarar esse processo a partir do materialismo histórico nos conduz à ideia de que a produção e a reprodução da vida - e não apenas o fator econômico - determinam a história $\left(\right.$ ENGELS, $\left.1890^{4}\right)$. No marxismo, fica evidente que a base econômica é momento preponderante no materialismo histórico, "sendo lei determinante do desenvolvimento histórico" (LUKÁCS, 2010, p. 13).

A arte seria componente de uma superestrutura que só secundariamente determinaria o processo de desenvolvimento. Entretanto, esse caráter secundário de determinação não faz da superestrutura apenas um efeito a partir de causas das relações econômicas, num processo mecânico. Evidentemente, que o estágio evolutivo da arte não acompanha de forma invariável o estágio evolutivo do modo de produção e da economia. Todavia, a partir do método dialético chegamos à existência de inter-relações causais entre essa superestrutura e a base econômica, fator esse que exprime a necessidade de considerarmos a arte como elemento constituinte do processo de desenvolvimento econômico, porém, sem o caráter reativo a ela muitas vezes atribuído.

\section{O caráter materialista da estética}

É necessário reforçar novamente que tanto Marx quanto Engels nunca se propuseram a estudar a estética, nem mesmo a arte como algo autônomo. Nem mesmo seria possível afirmar que o desenvolvimento de uma teoria sobre a arte seria intento de Marx e Engels, como sinaliza Williams (2011b). Entretanto, a base materialista histórica das obras de Marx e Engels traz elementos que possibilitaram a constituição de uma estética. A concepção de estética adotada neste artigo tem como base pressupostos materialistas, particularmente, os desenvolvidos por Lukács. O percurso realizado por Lukács afasta da estética possibilidades de uma completa abstração e universalidade no belo, como sentenciam as bases filosóficas de fundamentação platônica. Em Lukács (1966a), estética, como a própria produção artística, tem sua imanência do real, no concreto, nas contradições da própria vida. É representativa do estágio de desenvolvimento da produção capitalista, bem como do trabalho. A estética - e também a ciência - implica necessariamente a atividade produtiva, de forma que caracterize a "reciprocidade entre os elementos da superestrutura idealista e as relações materiais" (PAÇO-CUNHA, 2011, p. 11), de forma que não apenas a realidade e as relações de produção incidam sobre a arte, como esta se reconverte tanto sobre as realidades quanto sobre as relações de produção.

A abordagem materialista empregada por Lukács se difere da perspectiva estritamente subjetiva da estética, como pode ser verificado em Kant, para o qual "qualquer conformidade a leis e conceitualidade objetiva sejam afastadas da estética” (LUKÁCS, 1970, p. 20), uma vez que o juízo estético constitui apenas a faculdade de se julgar as coisas a partir de uma regra, mas não segundo conceitos. Para Lukács (1970), a estética em Kant se apresenta não apenas subjetivista, mas também formalista: "o afastamento do conceito importa na dissolução do conteúdo". Nesse caso, a imaterialidade estética se dá no "conhecer do homem" de modo ingênuo e acrítico; por consequência, sua produção artística.

Embora Kant tenha tirado a arte do limbo das reflexões, para o autor a criação artística se dá de forma descompromissada em face do real, uma vez que "a obra de arte não tem outro sentido, ou objetivo, que não ela mesma; por consequência, ela se torna, a partir de Kant, a obra de uma atividade humana (individual) que

${ }^{4}$ Carta de Engels a Conrad Schmidt, 27 de outubro de 1890. (MARX e ENGELS, 2010). 
se realiza com uma finalidade em si" (LEFEBVRE, 2001, p. 16). O aspecto subjetivista da estética e da produção artística pode ser visto em sua intensidade máxima quando Kant caracteriza a figura do gênio e do processo (quase) voluntário de sua produção artística.

Se depois destas análises lançamos um olhar retrospectivo sobre a explicação dada acima acerca do que se denomina gênio, encontramos: primeiro, que ele é um talento para a arte, não para a ciência, a qual tem de ser precedida por regras claramente conhecidas que têm de determinar seu procedimento; segundo, que como talento artístico ele pressupõe um conceito determinado do produto como fim, por conseguinte entendimento, mas também uma representação (se bem que indeterminada) da matéria, isto é, da intuição, para a apresentação deste conceito, por conseguinte uma relação da faculdade de imaginação ao entendimento; terceiro, que ele se mostra não tanto na realização do fim proposto na exibição de um conceito determinado, mas muito mais na exposição ou expressão de ideias estéticas, que contém uma rica matéria para aquele fim, por conseguinte ele representa a faculdade da imaginação em sua liberdade de toda a instrução das regras, e no entanto, como conforme a fins para a exibição do conselho dado; finalmente, quarto, que a subjetiva conformidade a fins espontânea e não intencional, na concordância livre da faculdade da imaginação com a legalidade do entendimento, pressupõe uma tal proporção e disposição destas faculdades como nenhuma observância de regras, seja da ciência ou da imitação mecânica, pode efetuar, mas simplesmente a natureza do sujeito pode produzir. (KANT, 1995, p. 163)

A elaboração estética em Kant reside única e exclusivamente na capacidade natural do homem de expressar suas ideias de forma espontânea e não intencional. Trata-se de um "exemplar do dom natural do sujeito no uso livre de suas faculdades de conhecimento". O caráter idealista subjetivista restringe a expressão estética ao seu aspecto singular, imanente à capacidade humana, ausente de determinações materiais. Para Lukács (1970), é justamente a ausência de uma relação dialética entre o universal e o particular na estética de Kant que a mantinha subjetiva, privada de objeto e conceito. Por ser a realidade objetiva de natureza dialética, todo comportamento prático e intelectual do homem, bem como seu reflexo da realidade, devem se adequar a esse caráter dialético (LUKÁCS, 1966b). A concepção idealista atribui às produções artísticas o papel catalizador de todo o princípio estético unitário, em suas origens, quando este se origina efetivamente de relações diversas com a própria arte, baseado "numa unidade objetiva desta (a arte), e na diversidade qualitativa dos órgãos receptivos e seu desenvolvimento histórico-social, diversas atividades, objetividades, receptividades etc., artísticas" (LUKÁCS, 1966a, p. 241).

A saída para essa abstração reside na estreita aproximação entre a arte e a realidade, de forma que a elaboração estética seja possível através do reflexo da realidade objetiva da vida material impressa na obra. Em seus escritos, Diderot inaugura, de certa maneira, uma elaboração que estabelece diretamente o elo entre arte e realidade. Para Diderot, a obra de arte parte do real através de uma elaboração na qual a relação entre obra de arte e o real representa os problemas existentes da realidade (LEFEBVRE, 2001).

O caráter estético da produção artística ligada ao real se aprofunda nos estudos de György Lukács. Em Lukács (1966a), a produção artística, assim como a produção material originária do trabalho, é resultado de um homem que vive em sociedade junto com outros homens, que na sociedade desenvolve suas capacidades mais vitais e que, por isso, apresenta tendências profundamente comuns aos outros homens que com ele vivem. O reflexo se diferencia do tratamento dado pela filosofia idealista moderna, para a qual o reflexo da realidade objetiva é meramente uma fotocópia da realidade, sem fundamentação e análise (LUKÁCS, 1966b).

A superação de uma perspectiva idealista e metafísica acerca da produção artística e da própria formulação do pensamento por Lukács passa necessariamente pela teoria do reflexo, apoiada em dois axiomas (PATRIOTA, 2010). O primeiro deles vai de encontro à tese idealista para a qual a verdadeira realidade é 
ideal, "sendo a sensibilidade, quando muito, uma região de trânsito para este plano superior". Para Lukács, a realidade é inexoravelmente materialista, vazia de essências metafísicas. O segundo axioma delega ao reflexo intelectual um caráter não mecânico, mas dinâmico, a partir da elaboração "que seleciona e reordena as categorias da realidade objetiva" (PATRIOTA, 2010, p. 17).

Em Hegel, o problema da concepção idealista a respeito da produção artística prevalece, de forma que a arte seja encarada como produto da ideia. Toda formulação de seu caráter prático e social se dá a partir da ideia, de um mecanismo sensitivo que produz o belo como a própria história da arte, assim como a ideia absoluta produz a história universal (LEFEBVRE, 2001).

A história da arte, assim como a da consciência (fenomenologia) ou do conhecimento (lógica) é, portanto, a história das formas ou estágios sucessivos que recobre - por se manifestar no tempo e no sensível - a ideia. A arte é uma emanação da ideia absoluta. O conteúdo da arte, em sua aparência prática e social, é basicamente constituído pela ideia. A arte apresenta o mesmo conteúdo da religião. Ela pode desaparecer no universo do espírito religioso e filosófico! A ideia absoluta se apresenta na arte sobre o aspecto do belo; a ideia do belo se realiza na história da arte da mesma forma que a ideia absoluta se realiza na história universal. (LEFEBVRE, 2001, p. 19)

O caminho percorrido desde o idealismo kantiano até o materialismo histórico e dialético, entre o universal e o particular, passa - entre outras importantes reflexões na filosofia - pelo reconhecimento dessa dialética por Hegel quando da análise da revolução democrática. Esse reconhecimento está no esfacelamento da concepção idealista acerca do caráter universal que o citoyen diante do bourgeois deveria assumir após a queda de Napoleão. Nesse caso, a encarnação do burocrata por parte do citoyen confere a ele o estrato universal. Isto é, o que se consagra a serviço do governo deve ter no universal a finalidade de sua atividade essencial. Todavia, é justamente por desvelar os interesses das velhas classes (bourgeois) - as quais visavam apenas seus interesses de classe (o particular), em detrimento da defesa dos anseios de toda a sociedade (o universal) - que Hegel sinaliza a dialética do universal e do particular. Conforme ressalta Lukács (1970), o movimento dialético se completa ao observar que a nova classe revolucionária (citoyen) representava apesar de lutar pelos seus próprios interesses (o particular) - o interesse de todos os prejudicados pelo antigo regime (o universal).

Lukács destaca esse movimento dialético do particular e do universal em Marx, quando na Ideologia alemã é ressaltada a necessidade de conquista do poder político por parte de toda e qualquer classe que almeje a dominação, mesmo quando essa dominação implica a superação de toda velha forma de sociedade e de dominação em geral, a fim de representar o interesse universal, dado que os indivíduos buscam apenas o seu interesse particular, que não coincide com o interesse coletivo. Porém, o universal é visto aqui como uma forma ilusória de coletividade, anunciada como interesse universal, não obstante esse interesse universal ser, de fato, particular e específico. Como exemplo, temos a crítica que Marx fez a Hegel por este imputar um caráter universal à burocracia, vista por aquele como a consciência e a vontade do Estado agindo, na verdade, como um particular que protege uma imaginária universalidade de seu único interesse.

A crítica de Marx a Hegel se concentra no aspecto universal, não apenas por este se tratar de uma categoria do pensamento científico - diante do qual o marxismo vai de encontro ao idealismo e à metafísica - mas também em virtude de uma definição errônea da categoria universalidade que acaba por fazer uma apologia ao capitalismo.

Pode-se ver como a apologética - do ponto de vista metodológico - parte do fato de que uma generalização justificada dentro de certos limites é ampliada de um modo ilimitado; este resultado só se pode obter na medida em que o conceito de universalidade é "libertado" de toda relação dialética (determinação, limitação, enriquecimento, concretização etc.) com a particularidade. A formulação apologética e abstrata do universal, portanto, liquida ao 
mesmo tempo a dialética do universal e do particular, ou - no máximo - permite apenas uma pseudodialética formalista. (LUKÁCS, 1970, p. 78)

É no movimento dialético entre o universal e o particular que se situam as determinações. Determinações estas que devem ser compreendidas para que o aspecto universal não recobre seu sentido natural contido na metafísica, e que as formas de produção e das demais instâncias mediadoras possam ser analisadas em seus elementos específicos, como explícito na análise de Marx (2011) acerca da apologia de uma natural universalidade do capital, que só seria possível caso se abandonasse o elemento específico que é o único que faz de um instrumento de produção, de um trabalho acumulado, um capital.

O capital, entre outras coisas, é também instrumento de produção, também trabalho passado, objetivado (objektivierte). Logo, o capital é uma relação natural, universal, eterna; quer dizer, quando deixo de fora justamente o específico, o que faz do "instrumento de produção", do "trabalho acumulado", capital. (MARX, 2011, p. 41)

A partir desse prisma, a dialética entre o universal e o particular permite justamente compreender os elementos específicos que agem sobre o real, constituindo dialeticamente o universal e o particular. Somente a partir de uma análise concreta é possível observar a relativização dialética do universal e do particular. Um se converte no outro a partir de determinadas situações concretas; o universal se especifica e se torna particular em determinadas relações ou se expande de tal forma que anula a particularidade. Por outro lado, é possível que esse particular se desenvolva até a universalidade. Comum a todo e qualquer movimento é o desvelar das contradições existentes a partir de uma abordagem dialética do universal e do particular.

A crítica de Marx às mistificações idealistas hegelianas transcende a crítica pura e simples ao idealismo absoluto e à dialética idealista. A dialética do universal e do particular a partir da análise concreta vai de encontro às ideologias burguesas que se alojam na universalidade fetichizada, a partir da contraposição do homem à totalidade. Estabelecer a dialética do universal e do particular permite justamente que este represente a "expressão lógica das categorias de mediação entre os homens singulares e a sociedade" (LUKÁCS, 1970, p. 85), evitando, segundo Marx (2004), a concepção de sociedade como uma abstração ante o indivíduo. A abstração idealista não deve ser encarada como ponto de chegada do pensamento. Ao contrário, reside no concreto o resultado, a síntese de múltiplas determinações. Ademais, reside nele também o ponto de partida, o iniciar de toda intuição e da representação (MARX, 2008).

Diferentemente do que possa ser inferido por uma ótica idealista, a universalidade "não é jamais um ponto de chegada autônomo do pensamento" (LUKÁCS, 1970, p. 95). Ao contrário, realiza-se aqui um movimento do particular-universal e do particular-singular, sendo dois os caminhos que o conhecimento humano deve percorrer: da realidade concreta dos fenômenos singulares às abstrações e desta, novamente, à realidade concreta, que com a ajuda das abstrações, poderá ser compreendida de um modo cada vez mais próximo do exato (MARX, 2011). Aqui se instaura a concepção de ciência a partir da dialética do universal e do particular, em que a concretização de uma universalidade superior conduz, ao mesmo tempo, a descobertas de novas formas de particularidade e a "determinações, limitações e especificações da nova universalidade tornada mais concreta".

Além disso, a partir da transição do universal para o particular, ou seja, a especificação das leis universais, é possível compreender a unicidade (a singularidade) de uma determinada situação diante da relação total e recíproca das "leis conhecidas, universais e particulares (LUKÁCS, 1970, p. 95-97). Esse singular, o caráter único manifesto na vida, só existe na sua relação com o universal, e o universal, só existe no singular. Para Lukács (1970, p. 101), o "movimento dialético da realidade, tal como se reflete no pensamento, é assim um incontrolável impulso do singular para o universal e deste, novamente, para aquele". Nesse movimento dialético, o particular operacionaliza a mediação, embora esta possa ser exercida tanto pelo universal quanto pelo singular, de forma que seja necessário compreender a relação dialética do singular-particular-universal. 


\section{A centralidade do particular na estética}

A função mediadora da particularidade que opera na singularidade e na universalidade constitui um ponto médio, um ponto que capta a transitoriedade dos extremos e desvela o reflexo estético, a reprodução da vida material e suas contradições na obra de arte. O reflexo artístico tem sempre como base a sociedade em sua relação com a natureza. Só pode expressar essa natureza sobre a base da sociedade, de forma que as relações materiais da vida suportem a expressividade do reflexo estético, ou inversamente, que o reflexo estético seja em si a realidade refletida (LUKÁCS, 1966a).

A singularidade está estreitamente ligada ao contato primário do homem com o objeto e à relação estabelecida entre este e outros objetos. Um objeto singular percebido se apresenta diante de nós como conhecido a partir do momento em que conseguimos relacionar as características desse objeto diante de outros que lhe são análogos. Assim, assumimos que esses objetos, apesar de singulares, apresentam propriedades que indicam suas conexões (LUKÁCS, 1967a). A percepção e a representação que criamos desses traços comuns dos objetos singulares, seus nexos, nos levam a uma generalização conceitual - como ocorre com a linguagem. No caso da linguagem, Lukács (1967a) destaca que o processo de generalização demanda, antes, um trabalho de captação muito preciso da objetividade e, por consequência, uma expressão mais exata possível das determinações específicas do objeto singular em análise, ao mesmo tempo em que abarca as conexões desse objeto com outros.

O processo de universalidade e conceituação exposto por Lukács (1967a) na análise da linguagem também contém em si diferenciações que nos permitem captar a peculiaridade da particularidade, tanto na prática quanto na reflexão sobre essa prática. A referência tomada para uma universalidade concreta se encontra, de certa forma, próxima da singularidade de um objeto observado, preservando momentos essenciais de uma aparente singularidade imediata. Por outro lado, absorve na própria universalidade a singularidade do objeto, suspendendo-a, de forma que esta só reapareça quando da aplicação dos aspectos gerais a um novo caso singular concreto. De acordo com Lukács (1967a), a questão da particularidade surge exatamente quando esse processo se dá de forma consciente, em sua reação com a singularidade e universalidade, de maneira que a consciência perceba e converta os objetos em pensamento, pensamento este que não representa um ponto final, mas que está diretamente conectado com a realidade. A particularidade não opera como uma universalidade relativa, ou como um caminho que leva o objeto singular à sua universalização (e vice-versa). A particularidade deve ser encarada como "a mediação necessária - produzida pela essência da realidade objetiva e imposta ao pensamento por ela mesma - entre a singularidade e a universalidade" (LUKÁCS, 1967a, p. 202).

O reflexo estético caracteriza a expressão da universalidade operada na particularidade do objeto artístico. Evidentemente que outras nuanças implicam a objetividade da forma e do conteúdo artístico. Além disso, deve-se ressaltar que a obra de arte não contém em si todo caráter extensivo de seu objeto real, mas sim expressa em seu conteúdo e forma a totalidade intensiva a partir de mediações em movimento (LUKÁCS, 1966a). A obra de arte, que contém em si o reflexo estético, depende do período, do gênero e da individualidade do artista, mas deve, necessariamente, discutir a totalidade dos problemas de sua época. A inexistência dessa discussão nas obras sinalizaria a carência de real universalidade e a enunciação de universalidades não retratadas artisticamente - falsas e distorcidas como conteúdo. Sendo a arte um meio de tomada de consciência do mundo exterior, seu caráter estético se caracteriza como o reflexo da realidade a partir do olhar do artista e da apreensão do objeto artístico (LUKÁCS, 2010).

Essa relação da obra de arte com os problemas da realidade na conversão da singularidade-particularidade e da particularidade-universalidade ressoa também na teoria do conhecimento. Nesta o real conteúdo é a posição da obra de arte diante da realidade, o modo, a intensidade e a profundidade com que a obra de arte mostra a realidade, ou seja, o reflexo estético. É justamente na particularidade que se manifesta essa posição da obra de arte em face da realidade, bem como sinaliza Lukács (1970) ao diferenciar o drama e o épico, sugerindo que "o drama tende geralmente a estabelecer mais perto da universalidade o ponto central da 
cristalização no particular, enquanto este ponto parece na épica ser impulsionado na direção da singularidade" (LUKÁCS, 1970, p. 156-157).

É necessário situar que a distinção entre os gêneros reflete a diferenciação histórica do seu tempo, além de trazer particularidades distintas no processo de mediação do singular e do universal, ora tendendo se aproximar de um dos extremos, ora de outro. Para Lukács, caracteriza-se aqui um velho e difícil problema da estética, ao considerar a unicidade e a incomparabilidade da obra de arte, que para Kant se resolvia no belo a partir das regras oferecidas na natureza ao sujeito - donde recobra a figura do gênio em sua plenitude, já mencionada anteriormente. Kant (1995) esboça claramente a impossibilidade de se estabelecer regras para uma lei estética, dado que, para ele, a obra de arte é o singular produto da subjetividade humana. A primazia do belo se dá a partir de uma antinomia. De um lado, o juízo do gosto determina o belo a partir do ângulo de contemplação, sendo essa contemplação pretensiosamente objetiva. Por outro lado, esse mesmo juízo não pode ser demonstrado, ocorrendo de forma subjetiva (LIFSCHITZ, 2010).

Lukács (1970) sinaliza que o problema das leis estéticas nas obras de arte permanece, não obstante o pensamento metafísico kantiano. A resposta está na formulação geral das contradições do desenvolvimento artístico, de forma que o particular, carregado de mediações concretas, possa ser o intermédio concretizante, negando o curso que vai da regra (abstrato universal) ao singular (gênio). O particular é, no reflexo estético, o ponto central organizador de um campo em movimento, tanto ponto de partida quanto de chegada (LUKÁCS, 1967a).

No reflexo estético, a particularidade na arte não é uma instância que pretende se apresentar ao mesmo tempo como ideia e realidade objetiva. A obra de arte, ou seja, a forma autônoma da particularidade, é uma criação humana e não pretender ser a realidade tal qual é a realidade objetiva. A obra de arte se coloca à nossa frente como uma "realidade" a partir das nossas ideias, desejos, de forma que nós não possamos alterála, cabendo a nós aceitá-la como tal ou rejeitá-la subjetivamente. O reconhecimento do ser diante da obra de arte e as contradições da vida concreta que a obra apresenta se dão pela elevação da singularidade ao nível da particularidade, a partir da sensibilidade imediata. Através desse mecanismo a obra emana o particular em cada singularidade. Da mesma forma, somente assim a obra pode incorporar e oferecer a essa experimentação a particularidade de um mundo representado. É a partir desses movimentos que a obra reflete a estrutura da realidade objetiva, sendo "um reflexo de nexos e de formas fenomênicas essenciais da própria realidade", como bem sentencia Lukács (1970, p. 164). Os caminhos percorridos pela verdadeira obra de arte se originam na realidade social e sua eficácia só é assegurada se esta obra for reconduzida à realidade social.

\section{A Subjetividade Estética e a Categoria da Particularidade}

A questão da subjetividade estética da obra de arte traz consigo não apenas a expressão da personalidade artística criadora, mas também, a produção artística coletiva que conserva o caráter da particularidade. Por exemplo, obras singulares de artistas com colaboração de individualidades diversas, mas que retêm algo que as distinguem das obras "similares", revelando suas individualidades.

Há que se diferenciar aqui, mais uma vez, as manifestações artísticas das científicas. No caso das colaborações científicas, as contribuições intelectuais individuais, as experiências pessoais, unem-se na realidade objetiva independentemente da consciência humana. É essa aproximação da realidade objetiva que determina o modo de união das personalidades, destaca Lukács (1970). Na arte, se a colaboração entre indivíduos resulta numa autêntica obra, essa obra conserva em si uma individualidade própria essencial, unitária. Efetivamente, as subjetividades dos indivíduos que participam do processo criativo produzem um efeito positivo quando forem capazes de se tornar um elemento estrutural da individualidade da obra. O que diferencia a colaboração científica da colaboração artística é que a primeira é dada pela universalização objetivadora. Já a colaboração artística requer também uma generalização que vá além da subjetividade 
particular imediata, mas uma generalização que resulte na "específica forma fenomênica da particularidade, como meio organizador da obra de arte" (LUKÁCS, 1970, p. 181).

A realização da obra de arte pelo homem, como elemento central da esfera estética, representa um elo entre a unidade orgânica da interioridade do homem com seu mundo externo. Aqui a expressão artística se caracteriza por atribuir forma à personalidade do homem diante do mundo, produzindo a superação de dois extremos, a singularidade e a universalidade, o próprio homem e o mundo (LUKÁCS, 1967a). O homem não perde sua subjetividade, mas ao emprestá-la à obra de arte, faz com que ela pertença em sua objetividade a toda relação material do mundo, reconhecida em seu caráter de particularidade. $\mathrm{O}$ artista, em seu ato de criação, é fundamentalmente livre. Todavia, trata-se de uma liberdade não abstrata, e sim, diretamente conectada ao concreto diante do qual o objeto artístico e o artista não podem se descolar. Uma liberdade incrustada nas determinações materiais e nas lutas de classe em diversos estágios do desenvolvimento da humanidade (LEFEBVRE, 2001), que atravessa os elementos superestruturais, mas sempre recobra seu sentido na base.

Essa relação entre objetividade e subjetividade, e a arte como conteúdo particular da realidade a partir da estreita aproximação do sujeito ante as questões da vida foram alvo de críticas. Nesse sentido, destacam-se as de Adorno (1993), que considerava a expressão artística além do reflexo da realidade pelo sujeito, dado que esse sujeito é capaz de realizar metamorfoses radicais da realidade empírica em sua elaboração artística (TERTULIAN, 2010).

Contudo, a subjetividade operacionaliza a elaboração artística, demarca a figura artística. Embora seja elevada à esfera da particularidade, acima da subjetividade imediata, conserva algo de subjetivo, de pessoal. Sua objetividade é balizada não pelo caráter generalizante da ciência, mas pelo modo como a subjetividade universalizada na particularidade pode reproduzir a realidade, através do reflexo estético. A relação entre objetividade e subjetividade na produção artística não é causal, mas, sim, reflete na estrutura objetiva da obra de arte como algo que se apresenta de um modo determinado (LUKÁCS, 1966a). Objetividade e subjetividade são inseparáveis na análise estética, de forma que a elaboração da estética lukácsiana não sublime a capacidade do homem.

A manifestação conjunta da subjetividade e da objetividade refuta por completo a concepção que iguala a expressão subjetiva imediata e a criação artística, o que para Lukács significaria um mundo solipsístico na obra de arte, sem seu conteúdo essencial, resultando numa subjetividade abstrata e esteticamente falaciosa, geradora de um objetivismo abstratamente desumano. Ao contrário, o caráter particular da obra de arte age sobre a personalidade do criador, assim como influencia todos a quem ela se dirige. A organização da obra na particularidade individual rompe com a ideia da subjetividade imediata, pois traz em si todas as reações do homem diante dos fenômenos da vida, o que não exclui suas experiências nem o produto de sua consciência perante a vida. Para Lukács (1967a), na elaboração da obra de arte e no reflexo estético, as conviç̧ões do homem, seus preconceitos e sua visão de mundo desempenham um papel fundamental. No cotidiano do homem, o reflexo da realidade já é demarcado pelos conflitos da vida. Porém, no processo criador artístico esses conflitos e dilemas demandam posições através do reflexo estético, caracterizando a concepção de mundo do artista. É nesse momento que se dá a transição da singularidade imediata - suas concepções - para a generalização estética, sua particularidade, manifesta na obra de arte, que deve contemplar em si o esforço de reprodução da realidade e todas as suas contradições.

Há que se ressaltar que o caráter objetivo da formulação estética não diz respeito a uma suposta neutralidade do artista diante dos fenômenos sociais. Pelo contrário, a produção artística só é possível a partir da tomada de consciência, que já contém em si a tomada de posição quando considerarmos que a criação artística não se origina de algo estático, mas sim processual. Dessa forma, é possível verificar que a objetividade da estética marxista não está em oposição ao caráter subjetivo do artista, mas sim presente na representação da obra que passa pela sua visão de mundo, singular (contendo em si subjetividade) e que se expressa através do reflexo da realidade: a objetividade estética (LUKÁCS, 2010). A subjetividade está já impressa no próprio reflexo da 
realidade, incluindo o nível da simples percepção que está diretamente conectado aos interesses vitais dos homens (LUKÁCS, 1966b).

\section{Partidarismo e Tomada de Posição na Obra de Arte}

A subjetividade estética se manifesta na particularidade que concentra em si a posição do artista diante da realidade, as contradições e conflitos da vida, por meio do reflexo estético e sua unidade mediadora na particularidade. Aqui se apresenta a principal diferenciação ante a concepção científica - e por sua vez o reflexo científico - que se instaura na universalidade objetivadora. O caráter do partidarismo no reflexo estético mediado no particular reforça sobremaneira a expressão artística como manifestação dessa tomada de posição, como bem define Lukács.

Se quisermos agora compreender conceitualmente o caráter do partidarismo no reflexo estético da realidade, deveremos observar que se trata, por um lado, da reprodução o mais possível fiel da própria realidade objetiva, mas que, por outro lado, a finalidade a que aqui se visa não é compreender conceitualmente as leis universais, e sim representar mediante imagens sensíveis um particular que compreende em si e supera em si tanto sua universalidade quanto sua singularidade, cujas características formais não pretendem uma aplicação universal no sentido da ciência, mas tendem a fixar universalmente uma experiência que assumiu a forma deste determinado conteúdo. (LUKÁCS, 1970, p. 195196)

Essa concepção do "compreender o caráter do partidarismo" evoca mais uma vez a diferença que o reflexo estético apresenta em face do reflexo científico, uma vez que apresenta desde o primeiro momento a tomada de posição diante das lutas históricas do momento em que vive o artista. O processo de produção artística é intrínseco a essa tomada de posição porque a produção artística, como toda produção, é também uma extensão da vida humana - como bem sinalizou Marx (2004) no processo de efetivação humana. Esta, por sua vez, está conexa com a emocionalidade partidária sempre necessária, ligada a posições afirmativas ou negativas diante das individualidades que movimentam a vida e os problemas da vida que nela se manifestam (LUKÁCS, 1970). O reflexo estético, a produção artística da realidade em seu nexo subjetivoobjetivo, é uma necessidade da própria vida (LUKÁCS, 1966a), de maneira que sua objetividade está também na possibilidade de trazer respostas aos problemas e conflitos, além de toda e qualquer caracterização metafísica das questões vívidas. Através da particularidade como categoria estética, o homem imprime sua identidade, sua proximidade ética diante do mundo em seu nexo material (LUKÁCS, 1967a).

A essência do partidarismo representa a tomada de posição diante do conteúdo, em conexão com os problemas concretos que sejam importantes para esse conteúdo, determinando, assim, a originalidade da obra de arte. As obras originais necessitam conter em si tomadas de posições justas ante os conflitos da vida, os problemas da época, sejam essas posições positivas ou negativas, mas que se materializem na forma correspondente a esse conteúdo, expressando-o adequadamente. Por ser a obra de arte a objetividade do particular, a representação da realidade, podemos afirmar que "a arte não pode representar nenhum fato ou relação fora de seu partidarismo" (LUKÁCS, 1970, p. 202). O fato aqui já é carregado de partidarismo, mesmo quando projetado como dado, uma vez que contém sempre atitudes positivas ou negativas diante da própria realidade. Nesse sentido, podemos assumir a produção artística e cultural, de forma mais ampla, como um artefato que é em si expressão diante de conflitos e lutas que marcam a sociedade a partir das questões materiais da vida, sendo, portanto, representativa de uma tomada de posição (WILLIAMNS, 2011a). 


\section{A arte como autoconsciência do desenvolvimento do ser social}

Ao tomarmos a produção artística como possibilidade de expressão humana de todas as suas relações materiais e determinações, trazemos já a implicação de que tanto na produção quanto na recepção da obra existe a possibilidade de transição de uma etapa do desenvolvimento para outra. A produção artística conserva no particular o mundo global, as relações com os outros homens, as mediações em face da natureza e as formas fenomênicas sensíveis. Ao mesmo tempo, incorpora o universal como força que determina a vida.

A superação das reais contradições da vida pela produção artística deve conter em si a consciência do caráter ideológico - que demanda, antes disso, consciência das próprias relações materiais - da arte em seu estágio atual e do curso do seu desenvolvimento. Ao assumirmos o processo histórico na perspectiva materialista, no qual se deve considerar que o desenvolvimento elabora sempre os resultados precedentes, é possível identificar na manifestação artística as etapas do desenvolvimento da humanidade, bem como as relações conteudísticas das elaborações da arte nas etapas anteriores do desenvolvimento, não obstante as propriedades humanas conservadas nas representações artísticas se apresentem em menor número que no desenvolvimento histórico. O reflexo estético da realidade particularizada na obra de arte como etapa do desenvolvimento da humanidade nos permite inferir que a superação do capital implica também a superação do seu caráter estético expresso nas obras de arte (LUKÁCS, 1970).

Do ponto de vista do indivíduo, a eficácia de sua elaboração artística o leva da mera singularidade do sujeito à particularidade. $\mathrm{Na}$ arte, o artista experimenta realidades que não lhes seriam possíveis de outra forma; nela está sua efetividade posicional diante das questões concretas da vida. A possibilidade de generalização na particularidade do reflexo estético é "precisamente o caráter social da personalidade humana" (LUKÁCS, 1970, p. 271). Em sua síntese, a produção artística representa a etapa de evolução não apenas do que o homem apreende conscientemente da realidade, mas da sua própria capacidade de representar essa realidade. A crítica de Adorno a Lukács sobre a pretensa imposição de exigências comumente empregada nas ciências sociais à arte, ignorando sua especificidade e o papel da subjetividade na elaboração artística (TERTULIAN, 2010), é superada na exata conexão objetividade-subjetividade elaborada em Lukács. Esta concentra em si toda a experiência vivida do homem a partir de uma determinação social, opera diretamente sobre o sujeito, ao contrário da ciência, que estabelece a partir de suas leis a realidade objetiva independente da consciência humana.

\section{Considerações Finais}

A partir do ponto de vista aqui levantado tornou-se necessária uma incursão pelos aspectos estéticos que consideram a produção artística diretamente conectada com o modo de produção e o desenvolvimento capitalista e, consequentemente, com a produção da própria vida e da sociedade. Em particular, a estética em Lukács nos permite estabelecer o nexo entre a atividade artística contendo em si não apenas seu atributo estético, mas, também, simultaneamente e de forma inseparável, o caráter ideológico, seu posicionamento diante das contradições impressas na sociedade.

Por consequência, a partir da produção artística, não como esfera do desenvolvimento espiritual concorrente ao desenvolvimento material, há possibilidade de manifestação do desacordo, da resistência, que como reflexo da realidade pode confluir para a tomada de consciência e a resolução dos conflitos na esfera material, pela práxis. Uma incursão que parte necessariamente da vida real, que reflete na superestrutura, mas com ressonância direta na base, nas relações estritamente materiais, na vida social.

Imputar à produção artística um resultado estético como reflexo da realidade estabelece um caráter transformador da vida social, de modo que a obra de arte possa representar de maneira efetiva, isto é, no seu resultado sobre as questões materiais, possibilidades de contrapor e superar as contradições existentes no 
capital. Além do mais, a concepção materialista da estética rompe com o caráter abstrato da criação artística e, ao mesmo tempo, coloca em xeque a figura do gênio kantiano cuja propriedade criativa se dá num puro exercício de imaginação.

Em bases marxianas, a elaboração estética é resultado das mediações sociais, fugidia ao caráter universalizante típico das atividades espirituais da superestrutura, mas também escapando ao caráter do singular, uma vez que a consciência só existe a partir do ser social. Assim, a particularidade opera a mediação da singularidade e da universalidade, de forma que o objeto artístico seja a realidade refletida em seu caráter universal - mas nunca a totalidade do real - e a singularidade, a partir das experiências do ser, de suas percepções.

A obra de arte como reflexo da realidade, como mecanismo de engajamento, não significa em absoluto uma reificação da capacidade produtiva pela concepção materialista da estética. O caráter subjetivo está impresso na unidade orgânica da interioridade do homem com seu mundo externo, pois através da obra de arte o homem imprime sua personalidade diante do mundo. A subjetividade do homem é emprestada à elaboração artística, de forma que a objetividade de seu produto concentre as relações materiais observáveis na particularidade da obra de arte.

O fato de conservar a subjetividade humana na obra de arte, imprimir em sua particularidade o caráter universal diante das contradições da vida social, faz com que uma concepção materialista da estética impute na obra de arte e no processo de sua elaboração uma tomada de posição. Diferentemente da ciência, que recobra pra si um caráter universalizante pretensamente explicativo de todas as relações da vida, a arte apresenta em si um espectro singular do universal mediado no particular, o qual invariavelmente contempla sua tomada de posição diante das contradições históricas no exato momento em que vive o artista.

É importante ressaltar que a elaboração artística, o reflexo estético, gera possibilidades de transformação nos elementos da superestrutura, onde residem, por exemplo, as esferas cultural e política. Entretanto, a arte opera não apenas em sua dialética interna, em sua contradição com as manifestações artísticas que a precedem ou com as que concorrem em seu tempo; fundamentalmente, essa tomada de posição só é possível porque a apreensão dos conflitos existentes na própria vida humana antecede a elaboração artística. Dessa forma, em sua dialética externa, a obra de arte parte das tensões materiais apreendidas das experiências do homem, retratadas a partir de mediações singulares. Posteriormente, através do conteúdo artístico expresso em sua particularidade, deve conter em si a consciência do homem, a partir de toda sua experiência vivida, retornando dialeticamente às relações materiais de base para a superação dos conflitos.

Esperamos com este estudo estimular pesquisas empíricas no campo da administração - em particular, nos estudos organizacionais - que tomem a produção artística a partir de sua relação ineliminável com as condições materiais. Dessa forma, o entendimento da essência dessas obras pode nos conduzir a uma ideia de transformação estética não apenas em sua dialética interna, àquilo que antecede a própria arte, mas fundamentalmente em sua dialética externa, como reflexo das contradições de ordem material. Além do mais, pensamos ser um argumento plausível à inserção de produções culturais historicamente marginalizadas na agenda das políticas públicas voltadas para a cultura, uma vez que essa inserção é também inserção do próprio indivíduo diante da realidade. 


\section{Referências}

ADORNO, T. Teoria estética. Lisboa: Edições 70, 1993.

; HORKHEIMER, M. A dialética do esclarecimento. Rio de Janeiro: Jorge Zahar, 1985.

KANT, I. Crítica da faculdade do juízo. 2. ed. Rio de Janeiro: Forense Universitária, 1995.

LEFEBVRE, H. Contribution à l'esthétique. 2. ed. Paris: Anthropos, 2001.

LIFSCHITZ, M. Prólogo. In: MARX, K.; ENGELS, F. Cultura, arte e literatura: textos escolhidos. 2. ed. São Paulo: Expressão Popular, 2010.

LUKÁCS, G. Ensaios sobre literatura. Rio de Janeiro: Civilização Brasileira, 1965.

Estética I: da peculiaridad de lo estetico. Barcelona: Ediciones Grijalbo, 1966a.

Estética II: el problema de la mímeses. Barcelona: Ediciones Grijalbo, 1966b.

Estética III: categorias básicas de lo estético. Barcelona: Ediciones Grijalbo, 1967a.

Introdução a uma estética marxista. 2. ed. Rio de Janeiro: Editora Civilização Brasileira, 1970.

Introdução aos escritos estéticos de Marx e Engels. In. MARX, K.; ENGELS, F. Cultura, arte e literatura: textos escolhidos. 2. ed. São Paulo: Expressão Popular, 2010.

MARX, K. O capital: crítica da economia política. São Paulo: Nova Cultural, livro 1, v. 2, 1996.

Manuscritos econômico-filosóficos. São Paulo: Boitempo, 2004.

Contribuição à crítica da economia política. São Paulo: Expressão Popular, 2008.

Grundrisse: manuscritos econômicos de 1857-1858: esboços da crítica da economia política. São Paulo: Boitempo, 2011.

; ENGELS, F. A ideologia alemã. São Paulo: Boitempo, 2007.

Cultura, arte e literatura: textos escolhidos. São Paulo: Expressão Popular, 2010.

PAÇO-CUNHA, E. As propriedades estéticas do trabalho como emanação de sua relação com o capital. In: ENCONTRO NACIONAL DOS PROGRAMAS DE PÓS-GRADUAÇÃO E PESQUISAS EM ADMINISTRAÇÃO, 25., 2011, Rio de Janeiro. Anais... Rio de Janeiro: Anpad, 2011.

PATRIOTA, R. A relação sujeito-objeto na estética de Georg Lukács: reformulação e desfecho de um projeto interrompido. 284f. Tese (Doutorado em Filosofia) - FAFICH, Universidade Federal de Minas Gerais, Belo Horizonte, 2010 .

WILLIAMS, R. Cultura e sociedade: de Coleridge a Orwell. Petrópolis: Vozes, 2011a.

Cultura e materialismo. São Paulo: Editora Unesp, 2011b. 